\title{
COMPARISON OF USE OF LOW DOSE VAGINAL MISOPROSTOL FOR SECOND AND EARLY THIRD TRIMESTER PREGNANCY TERMINATION IN WOMEN WITH PRIOR CAESAREAN AND UNSCARRED UTERI
}

\author{
GEÇİRILMISS SEZARYEN ÖYKÜSÜ OLAN VE UTERINN SKARI OLMAYAN GEBELERDE \\ IKIINCI VE ERKEN ÜÇÜNCÜ TRIMESTER TERMINASYONLARINDA DÜŞÜK DOZ \\ VAGINAL MIZOPROSTOL KULLANIMININ KARŞILASTTIRILMASI
}

\author{
Özlem DURAL*, Cenk YAŞA*, Deniz K. ACAR** Gökhan YILDIRIM**, Melih BESTEL**, \\ Sedat TEKELI**, Halil ASLAN**
}

\begin{abstract}
Objective: The study was aimed to determine the safety and efficacy of the vaginal administration of low dose misoprostol for late pregnancy termination in women with prior caesarean and unscarred uteri.

Study design: A retrospective study was carried out from January 2008 to June 2012 on 209 pregnant women who underwent termination of pregnancy in the second and early third trimester. Among the women, 173 did not have a uterine scar (Group 1) while 36 had a history of prior caesarean (Group 2). The induction-to-abortion interval, the rate of complications and failureand the need for a different method during the process were assessed.

Results: In group 1, 145 of patients (83.8\%) delivered vaginally in 48 hours, the mean duration of the induction-toabortion interval was $21 \pm 10.3$ hours. In this group, 11 patients $(6.3 \%)$ needed one or more different methods and one case of uterine rupture $(0.57 \%)$ was observed. In group 2, 26 of patients $(72.2 \%)$ delivered vaginally in 48 hours $(p=0.11)$, the mean induction-abortion interval was $22.7 \pm 10.8$ hours $(p=0.45)$. Six patients $(16.7 \%)$ needed a different method $(p=0.05)$ and there was also one case $(2.7 \%)$ of ruptured uterus $(p=0.28)$.

Conclusion: Administration of low-dose vaginal misoprostol appears to be effective without excessive side effects or complications for late pregnancy termination.
\end{abstract}

Key words: Misoprostol; pregnancy termination; uterine rupture

\section{ÖZET}

Amaç: Geçirilmiş sezaryen veya uterin cerrahi öyküsü olan ve olmayan hastalarda geç gebelik terminasyonlarında düşük doz vaginal mizoprostol uygulamasının güvenilirliği ve etkinliğinin belirlenmesi amaçlandı.

Yöntem ve Gereç: Ocak 2008 ile Haziran 2012 tarihleri arasında ikinci veya erken üçüncü trimesterde gebelik terminasyonu yapılan 209 gebe retrospektif olarak değerlendirildi. Gebelerden 173'ünde uterin skar bulunmazken (Grup 1), 36'sında daha önce sezaryen hikayesi mevcuttu (Grup 2). İndüksiyon ile abortus arasında geçen süre, komplikasyon oranı, başarısızlık oranı ve bu süreçteki ek girişim gereksinimi değerlendirildi.

Bulgular: Grup 1'deki hastaların145'inde $(\% 83,8)$, ilk 48 saatte vaginal doğum olurken, indüksiyonla abortus arasındaki ortalama süre $21 \pm 10,3$ saat idi. Bu gruptaki hastaların 11 'inde $(\% 6,3)$ bir veya daha fazla ek girişim gerekirken, bir olguda $(\% 0,57)$ uterin rüptür gözlendi. Grup 2'de ise hastaların 26'sında $(\% 72,2)$ ilk 48 saatte vaginal doğum olurken $(\mathrm{p}=0.11)$ indüksiyonla abortus arasındaki ortalama süre $22,7 \pm 10,8$ saat idi ( $\mathrm{p}=0.45$ ). Altı hastada $(\% 16,7)$ ek girişim gerekirken $(\mathrm{p}=0.05)$, bir olguda $(\% 2,7)$ uterin rüptür görüldü $(\mathrm{p}=0.28)$.

Sonuç: Geç gebelik terminasyonlarında düşük doz vaginal mizoprostol, belirgin yan etki veya komplikasyona sebep olmaksızın uygulanabilir görünmektedir.

Anahtar kelimeler: Mizoprostol; gebelik terminasyonu; uterin rüptür

Date received/Dergiye geldiği tarih: 24.01.2016 - Date accepted/Dergiye kabul edildiği tarih: 18.05.2016

* Istanbul University, Istanbul Faculty of Medicine, Department of Obstetrics and Gynecology,

** Kanuni Sultan Suleyman Training and Research Hospital, Department of Maternal and Fetal Medicine, Istanbul, TURKEY (Corresponding author/İletişim kurulacak yazar: cinozlem@hotmail.com) 


\section{INTRODUCTION}

Misoprostol, a synthetic prostaglandin E1 (PGE 1$)$ analog, is initially marketed for the prevention and treatment of peptic ulcers. The Food and Drug Administration (FDA) approved a new label for the use of misoprostol during pregnancy in 2002 (1) and the World Health Organization (WHO) also recommended the use of misoprostol in termination of pregnancy in various gestations (2). It is available in a tablet form that is can be stored at room temperature, cheap, available in most countries and formulated for oral use but is also effective by vaginal, buccal, or sublingual administration for the purposes of abortion (3).

There were many different studies talking about the use of misoprostol with high efficacy and low incidence of side effects for medical termination of second-trimester pregnancy (4-6). Although the optimal dose and route of administration have not been identified, vaginal administration is associated with shorter induction times and lower incidence of side effects except for transient fever compared to oral administration (7-9). Sublingual administration appears to be similar to vaginal and also is superior to oral (10). More research is needed before recommending buccal route when using misoprostol alone.

The ability of early prenatal diagnosis of fetal anomalies has increased the indications for termination of pregnancy in the second trimester (11). There is limited information on the safety of misoprostol for induction of labour to terminate pregnancy in women with prior uterine surgery. These reports focus on medical termination of second and third-trimester pregnancy including fetal demise with low dose vaginal misoprostol from 14 to 32 weeks in women with prior caesarean and unscarred uteri. Reasons for termination of pregnancy were fetal malformation and fetal demise.
We assessed the side-effects, effectiveness, and outcomes.

\section{METHODS AND MATERIAL}

This retrospective study was conducted between January 1st, 2008 and May 30, 2012 with 209 consecutive patients who underwent termination of pregnancy for fetal anomaly or after intrauterine fetal death in the mid-trimester and third-trimester, between 14 and 32 gestational weeks at a training and research hospital in Turkey. The patients in the series were divided into two groups. Group 1 consisted of 173 patients with unscarred uteri; Group 2 included 36 women with prior caesarean. 33 patients $(91.6 \%)$ had one and 3 (8.3\%) had two prior low transverse caesarean sections.

Misoprostol in doses of either 25, 50, 100 or 200 $\mu \mathrm{g}$ was given vaginally every 4 to 6 hours (h) to induce abortion in all cases. We reduced the dosage of the misoprostol applications beyond 23 weeks. Lower doses of misoprostol were also given to thepatients with a scarred uterus (Figure1). For pregnancies of 23 weeks of gestation or longer with a live fetus, feticide was done by injection into the fetal heart of potassium chloride. A failed labour induction abortion (Failure) was determined when the fetus was still not expelled within $48 \mathrm{~h}$ or the use of a additional method was needed (e.g., i.v. oxytocin). Oxytocin, ethacridine lactate or foley cathater were used as additional methods andthey were initiated if the abortion had not occurred within 48-60 h. We allow 12 to $24 \mathrm{~h}$ rest and then additional misoprostol was given vaginally to 13 patients with failed abortion. Complications analysed were uterine rupture and bleeding requiring blood transfusion.

The mean duration of the induction-to-abortion interval,

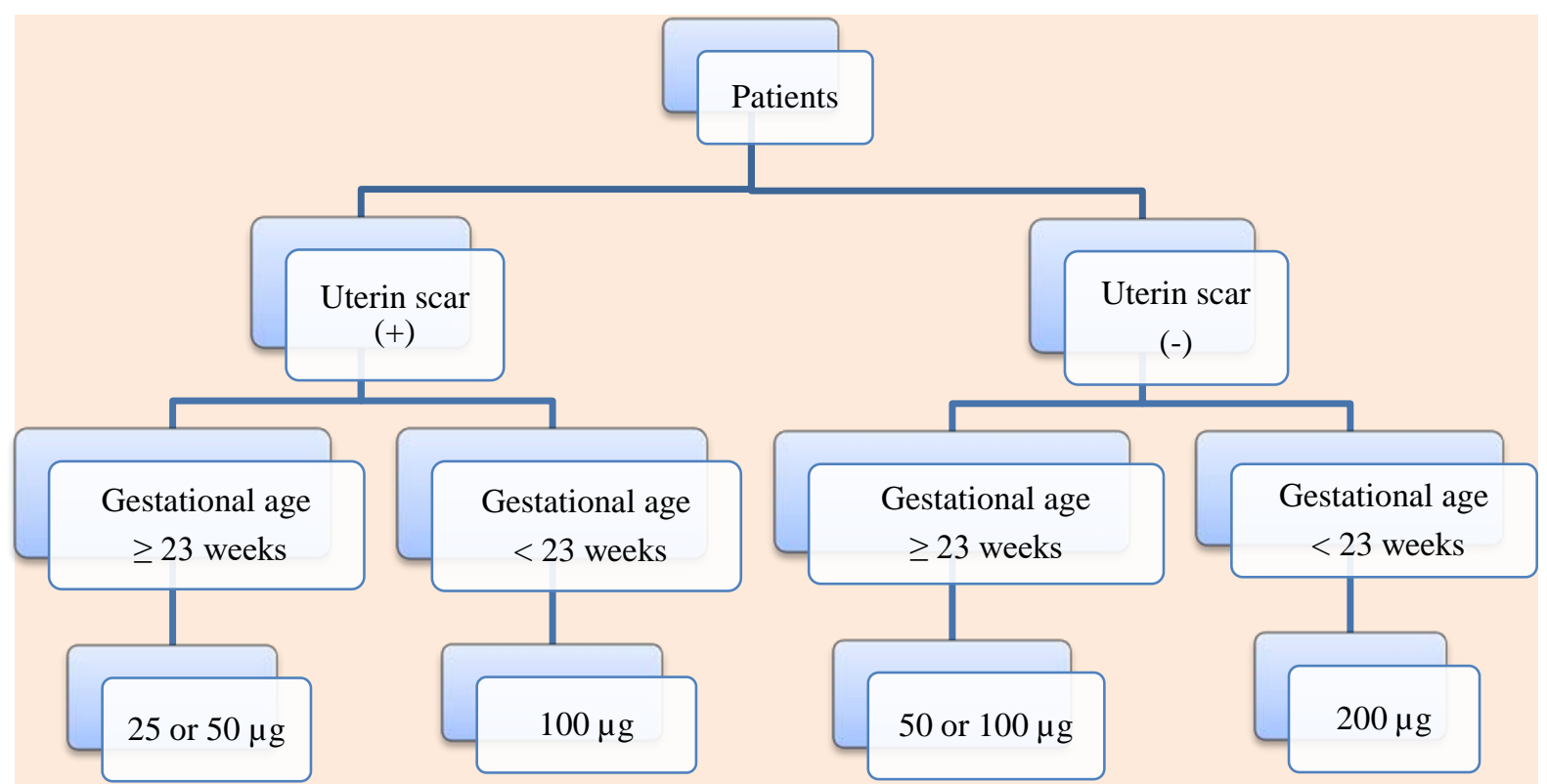

Figure 1: Our clinic protocol of misoprostol administered vaginally every 4 to 6 h for pregnancy termination (from 14 to 32 weeks).

the failure rate, the average total dose of misoprostol $(\mu \mathrm{g})$ and the complication rate were compared between
Group 1 and 2. The mean duration of the induction-toabortion interval, the failure rate and the rate of surgical 
evacuation of retained placenta were also compared according to parity, gestational age and spontaneous or induced (feticide) fetal demise among the patients of Group 1.

\section{Statistical analysis}

Microsoft Excel was used for data entry. For the purpose of analysis, we categorized patients into groups according to gestational age, parity and existence of fetal demise. Statistical analysis was performed with the Statistical Package fort he Social Sciences (SPSS) 17 (SPSS Inc, Chicago, IL). The results are presented as mean and standard deviation including relevant ranges, or as number and percentage. The relation between two quantitative variables was studied using the Student's $t$ or Mann Whittney $U$ tests depending on their distribution. $\quad \mathrm{P}<0.05$ was considered statistically significant.

\section{RESULTS}

This study included 173 women with a mean age of $27 \pm 6$ years in Group 1 and 36 women with a mean age of $29 \pm 6$ in Group 2. We analyzed these two groups separately. When we assessed Group 1, the indication for termination of pregnancy was fetal anomaly in 147 (84.9\%) of the 173 participants and there were 65 live fetuses (37.5\%) before labour induction. The mean gestational age was $22.07 \pm 4.6$ weeks (range, 14-32 weeks) in this group. Feticide was performed on 39 patients with a viable fetus after 23 weeks of gestation. A vaginal abortion occurred in 145 women (83.8\%) in 48 hours. The average total dose of misoprostol was $664 \mu \mathrm{g}$, which ranged from $100 \mu \mathrm{g}$ to $1800 \mu \mathrm{gr}$ and the mean duration from start of induction to delivery was $21 \pm 10.3 \mathrm{~h}$ in these patients. In $6.3 \%$ of patients $(n=11)$, the use of a different method was needed for termination of pregnancy. Thirteen patients with failed abortion were allowed to rest for 12 to 24 hours and then additional misoprostol was given vaginally. Nine of the 13 patients delivered within the ensuing additional 24 hours. Two of patients needed for a different method and another two patients delivered in 48 hours (Table 1 ).

Table 1: Clinical outcomes of induction in two groups

Parameter
Mean gestational age (weeks)
The induction-to-abortion interval (hours)
The average total dose of misoprostol ( $\mu \mathrm{g})$
The need for a different method \% (n)
Uterine rupture \% (n)

$\begin{array}{ccc}\begin{array}{c}\text { Group 1 } \\ (\mathbf{n}=\mathbf{1 7 3})\end{array} & \begin{array}{c}\text { Group 2 } \\ (\mathbf{n}=\mathbf{3 6})\end{array} & \text { p value } \\ 22.7 \pm 4.6 & 22.0 \pm 3.9 & 0.38 \\ 21.0 \pm 10.3 & 22.7 \pm 10.8 & 0.45 \\ 664.1 \pm 34.1 & 434.6 \pm 64.8 & 0.007 \\ 83.8 \%(\mathrm{n}=145) & 72.2 \%(\mathrm{n}=26) & 0.11 \\ 6.3 \%(\mathrm{n}=11) & 16.6 \%(\mathrm{n}=6) & 0.05 \\ 0.57 \%(\mathrm{n}=1) & 2.7 \%(\mathrm{n}=1) & 0.28\end{array}$

The induction-to-abortion interval (22.9 $\pm 10,3$ hvs $18.8 \pm 9.9 \mathrm{~h}, \mathrm{p}=0.01$ ) was significantly longer but the failed abortion rate was not statistically higher in the nulliparious patients $(16.4 \%$ vs $15.8 \%, p=0.91)$. The mean total dose of misoprostol was significantly lower (775.4 $\mu \mathrm{g}$ vs $600 \mu \mathrm{g}, \mathrm{p}=0.007$ ) and the time interval between the start of treatment and fetal expulsion was also shorter but the difference is not statistically significant $(22.5 \pm 9.8 \mathrm{~h}$ vs $20.1 \pm 10.6 \mathrm{~h}, \mathrm{p}=0.11)$ in patients with gestational age is greater than 20 weeks. Routine operative removal of the placenta was not performed (Table 2,3). The removal of retained products of the placenta or heavy vaginal bleeding were indications for surgical evacuation. The pregnancies less than 20 weeks had a higher rate of incomplete abortion and surgical intervention as compared to pregnancies greater than 20 weeks $(p=0.007)$. The dosage necessary to cause fetal expulsion was significantly lower (765.9 $\mu \mathrm{g}$ vs $492.6 \mu \mathrm{g}, \mathrm{p}<0.001$ ) and the induction process was typically shorter $(22.2 \pm 9 \mathrm{~h}$ vs $18.9 \pm 11.2 \mathrm{~h}$, $\mathrm{p}=0.022$ ) in pregnancies with spontaneous or induced (feticide) fetal demise (Table 4). No other statistically significant differences were observed.

One case of uterine rupture was occurred in Group 1 patients (0.57\%) after administration of $1200 \mu \mathrm{g}$ misoprostol in doses of $200 \mu$ g every 4 hours. She underwent emergency laparotomy and the uterus was repaired. Four units of blood transfusion is donebecause of severe vaginal bleeding. No other complication or significant side effect was observed in this group (Table 1). Afterwards, we analyzed Group 2. The indication for termination of pregnancy was fetal anomalyin 29 (80.5\%) of the 36 participants and there were 22 live fetuses (61.1\%) before labour induction. The mean gestational age was $22 \pm 3.9$ weeks (range, 15-32 weeks) in this group. Thirty three patients $(91.6 \%)$ had one and 3 (8.3\%) had two prior low transverse caesarean sections. A vaginal abortion occurred in 26 women $(72.2 \%)$ in 48 hours. The average total dose of misoprostol was $434.6 \mu \mathrm{g}$, which ranged from $50 \mu \mathrm{g}$ to $1200 \mu \mathrm{g}$ and the mean duration from start of induction to delivery was $22.7 \pm 10.8 \mathrm{~h}$ in these patients. In $16.7 \%$ of patients $(n=6)$, the use of a different method was needed for induction of labour. One case of uterine rupture (2.7\%) occured after administration of $275 \mu \mathrm{g}$ misoprostol in doses of 25 $\mathrm{gg}$ every 4 hours followed by oxytocin infusion, 10 units in 1 liter of D5RL, as an additional method by reason of a failed abortion in patient with one prior low transverse caesarean section 
at 20 weeks gestation and an emergency laparotomy, which involved repairing the ruptured uterus, was performed and three units of blood was administred during the procedure.

Table 2: Effects of parity

$\begin{array}{lccc}\text { Parameter } & \begin{array}{c}\text { Nulliparious } \\ \text { patients } \\ \mathbf{( n = 9 1 )}\end{array} & \begin{array}{c}\text { Primiparous and } \\ \text { multiparous patients } \\ \text { (n=118) }\end{array} & p \text { value } \\ \text { The induction-to-abortion interval (hours) } & 22.9 & 18.8 & 0.014 \\ \text { The average total dose of misoprostol ( } \mu \mathrm{g}) & 732.2 & 589.1 & 0.064 \\ \text { The failed abortion rate (\%) } & 16.4 & 15.8 & 0.91\end{array}$

Table 3: Effects of gestational age

$\begin{array}{lccc}\text { Parameter } & \begin{array}{c}\text { Patients } \leq \mathbf{2 0} \text { w } \\ (\mathbf{n = 7 5 )}\end{array} & \begin{array}{c}\text { Patients }>\mathbf{2 0} \text { w } \\ (\mathbf{n = 1 3 4 )}\end{array} & \boldsymbol{p} \text { value } \\ \text { The induction-to-abortion interval (hours) } & 22.5 & 20.1 & 0.115 \\ \text { The average total dose of misoprostol }(\mu \mathrm{g}) & 775.4 & 600 & 0.007\end{array}$

Table 4: Effects of fetal demise

$\begin{array}{lccr}\text { Parameter } & \begin{array}{c}\text { Alive fetus } \\ (\mathbf{n = 1 3 0 )}\end{array} & \begin{array}{c}\text { Spontaneous or induced } \\ \text { (feticide) fetal demise } \\ \text { (n=79) }\end{array} & \begin{array}{c}\boldsymbol{p} \\ \text { value }\end{array} \\ \text { The induction-to-abortion interval (hours) } & 22.2 & 18.9 & 0.022 \\ \text { The average total dose of misoprostol }(\mu \mathrm{g}) & 765.9 & 492.6 & <0.001\end{array}$

In Group 2, the average total dose of misoprostol $(\mu \mathrm{g})$ was signisficantly lower compared with Group 1 . Hovewer, the induction-to-abortion interval (hours), success rate, the rate of need for a different methodand uterine rupture rate were not significantly different between two groups (Table 1). No other complication or significant side effect was observed. The participants reported no serious side effects of misoprostol in both Group 1 and 2.

\section{DISCUSSION}

Misoprostol is widely used to induce labour for termination of pregnancy in the presence of an unfavorable cervix in the second and third trimesters. Vaginal or sublingual administration of misoprostol as a single agent is effectivefor labourinduction abortion. When misoprostol treatment is being used alone, vaginal dosing appears to be more efficient when compared to sublingual regimens for nulliparous women (10). The 2011 Cochrane Database Systemic Review also recommended that the most appropriate route for administrating misoprostol is vaginal (12). There is considerable variation in the dose and frequency of administration of misoprostol to terminate of pregnancy in the second or third trimester of pregnancy. Although there are insufficient data to make definite recommendations on the dosage and regimen for abortion induction, reducing the dosage or interval between administration should be considered at later gestational ages since the uterus becomes more responsive to uterotonic agents as gestation advances (13).

In our current study we chose the protocol of three different doses vaginal misoprostol administration (200, 100 or $50 \mu \mathrm{g}$ ) in women with unscarred uteri and three different doses $(100,50$ or $25 \mu \mathrm{g})$ in women with scarred uteri every 4 to $6 \mathrm{~h}$ according to the gestational age. It was suggested that 3-6 hours interval is a good choice for mid-trimester termination (14). Studies have also shown that misoprostol, 400 $\mu$ g given vaginally every 36 hours, is probably the optimal regimen for secondtrimester abortion $(15,16)$. We used mean total doses of $664 \mu \mathrm{g}$ in Group 1 and $434.6 \mu \mathrm{g}$ in Group 2. The means of induction to delivery interval was 21 hours with 83.8\% women undergoing vaginal delivery within 48 hours in Group 1. Other studies evaluating the safety and efficacy of misoprostol on scarred and unscarred uteri used doses higher than ours. Longer median abortion intervals in this study may be due to the relatively low misoprostol dosage. We allowed 13 patients with failed abortion 12 to 24 hours rest and then additional misoprostol was given vaginally. Nine of the 13 patients delivered within the ensuing additional 24 hours without serious side effects or complications. This rest may decrease the incidence of complications due to prolonged use of misoprostoland the need for a additional method. 
The study results showed that the median duration of abortion was significantly influenced by gestational age (17). The total dose of misoprostol also decreases with increasing gestational age (15). A statistically significant decrease was only found for the mean value of total required dose of misoprostol in patients greater than 20 weeks' gestation in our study. It was also found that multiparous women responded to vaginal misoprostol with a shorter induction-to-abortion interval than nulliparous women (17). Our results similarly revealed that nulliparity was associated with a signifcantly longer induction-to-abortion interval but not statistically higher percentage of failed abortion.

Uterine sensitivity to misoprostol may also be influenced by whether or not the fetus is alive at the time of induction. Pregnancies with spontaneous or induced (feticide) fetal demise may be treated similarly in most cases; however, the dosage necessary to cause fetal expulsion is lower, and the induction process is typically shorter $(18,19)$. Preprocedure feticide may facilitate the time to expulsion with labour induction abortion (10). Similarly, the dosage necessary to cause fetal expulsion was significantly lower, and the induction process was typically shorter in pregnancies with fetal demise in this study. Routine placental removal is not warranted (10). Indications for surgical evacuation were the removal of retained products of the placenta and heavy vaginal bleeding. The pregnancies less than 20 weeks had a higher rate of incomplete abortion and surgical intervention as compared to pregnancies greater than 20 weeks in our study.

Uterine rupture is a rare but serious complication of medical induction of abortion in the second trimester of pregnancy, especially in women with a previous uterine scar (20). Although prior hysterotomy is suspected to be a risk factor for uterine rupture during labour induction abortion, approximately one-half of uterine ruptures occur in unscarred uteri. However, for safety; it is recommended that women with a scarred uterus should receive lower doses of misoprostol and do not double the dose if there is no initial response (15). Goyal at al (21) conducted a systematic review included 16 studies and 722 participants in which the doses, routes of administration and between-dose intervals are considerably different. This review showed that the uterine rupture rate for women with one prior low transverse caesarean birth and subsequent second trimester misoprostol termination was $0.28 \%$.

The other current meta-analysis included 12 studies and 461 patients revealed that the uterine rate among women with one prior low transverse caesarean birth was $0.43 \%$ during second trimester pregnancy termination (20). The lowest total misoprostol dose administered prior to uterine rupture was a single dose of $200 \mu \mathrm{g}$ (22), but several women received multiple doses prior to uterine rupture. Augmentation with oxytocinmay increase the risk of uterine rupture in patients with previous cesarean delivery. The use of oxytocin as an additional agent in these women should also be minimised $(23,24)$. We used three different doses of vaginal misoprostol (25, 50 , or $100 \mu \mathrm{g}$ ) according to the gestational age with the same dosing intervals in Group 2. In 36 patients we observeda median time to delivery of $16 \mathrm{~h}$, with one case of uterine rupture. This uterine rupture occurred in woman who had an oxytocin infusion as a additional method by reason of a failed abortion.

In conclusion, administration of low-dose vaginal misoprostol appears to be effective without excessive side effects or complications for late pregnancy termination. Higher parity and spontaneous or induced (feticide) fetal demise is associated with shorter induction to abortion interval. The dosage necessary to cause fetal expulsion is also lower in pregnancy with fetal demise and inversly correlated with gestational age. The fact that there is no clear consensus or recommendations in literature on dose, route of administration and dosing interval of misoprostol for late pregnancy termination in women with prior caesarean and additional large randomized controlled trials are needed to confirm these results. There is also insufficient data to comment on the safety of second trimester termination in women with two or more lowtransverse caesarean births, or with prior classical incisions.

\section{REFERENCES}

1. New US food and drug administration labeling on Cytotec (misoprostol) use and pregnancy. ACOG Committee Opinion 283. Washington, DC: American College of Obstetricians and Gynecologists 2003. Int J Gynaecol Obstet. 2003;82:137-8

2. WHO. Safe abortion: technical and policy guidance for health system. Geneva: WHO; 2003.

3. Ho PC, Blumenthal PD, Gemzell-Danielsson K, Gomez Ponce de LR, Mittal S, Tang OS. Misoprostol for the termination of pregnancy with a live fetus at 13 to 26 weeks. Int J Gynaecol Obstet 2007;99(2):178-81.

4. Lehair J, Lemarie P, Helleringer M, Manini P. Expulsion of arrested pregnancy product in the second trimester using a prostaglandin E1 analog administered intravaginally. Apropos of 12 cases. Rev Fr Gynecol Obstect 1989;84:19-23.

5. Bugalho A, Bique C, Almeida L, Fau'ndes A. The effectiveness of intravaginal misoprostol (Cytotec) in inducing abortion after eleven weeks of pregnancy. Stud Fam Plann 1993;24:319-23.

6. Elsheikh A, Antsaklis A, Mesogitis S, Papantoniou N, Rodolakis A, Vogas E, Michalas S. Use of misoprostol for the termination of second trimester pregnancies. Arch Gynecol Obstet 2001;265:204-6.

7. Nigam A, Singh VK, Prakash A. Vaginal vs. oral misoprostol for mid-trimester abortion. Int $\mathrm{J}$ Gynaecol Obstet 2006;92:270-1.

8. Dickinson JE, Evans SF. A comparison of oral misoprostol with vaginal misoprostol administration in second-trimester pregnancy termination for fetal abnormality. Obstet Gynecol 2003;101:1294-9.

9. Bebbington MW, Kent N, Lim K, Gagnon A, Delisle MF, Tessier $\mathrm{F}$, et al. A randomized controlled trial comparing two protocols for the use of misoprostol in midtrimester pregnancy termination. Am J Obstet Gynecol 2002;187:853-7. 


\section{Gebelik terminasyonu için vaginal mizoprostol}

10. Borgatta L, Kapp N. Clinical guidelines. Labour induction abortion in the second trimester. Contraception 2011;84(1):4-18.

11. Hsieh TY, Yu CH, Kuo PL, Chang FM. Prenatal diagnosis of alobar holoprosencephaly with cystic hygroma. Taiwan J Obstet Gynecol 2006;45:146-9.

12. Wildschut H, Both MI, Medema S, Thomee E, Wildhagen MF, Kapp N. Medical methods for midtrimester termination of pregnancy. Cochrane Database Syst Rev 2011;19:CD005216.

13. Grimes DA. The continuing need for late abortions. JAMA 1998;280(8):747-50.

14. Lin CJ, Chien SC, Chen CP. The use of misoprostol in termination of second-trimester pregnancy. Taiwanese Journal of Obstetrics \& Gynecology 2011;50:275-82.

15. Elati A, Weeks AD. The use of misoprostol in obstetrics and gynaecology. Br J Obstet Gynecol 2009;116:61-9.

16. Lalitkumar S, Bygdeman M, Gemzell-Danielsson K. Mid-trimester induced abortion: a review. Hum Reprod Update 2007;13:37-52

17. Dickinson JE, Doherty DA. Factors influencing the duration of pregnancy termination with vaginal misoprostol for fetal abnormality. Prenatal Diagnosis 2009;29(5):520-4.

18. Jain JK, Mishell DR. Comparison of intravaginal misoprostol with prostaglandin-E(2) for termination of 2nd-trimester pregnancy. N Engl J Med 1994;331:290-3.

19. Dickinson JE, Evans SF. The optimization of intravaginal misoprostoldosing schedules in secondtrimester pregnancy termination. Am J Obstet Gynecol 2002;186:470-4.

20. V Berghella, J Airoldi, AM O’Neill, K Einhorn, M Hoffman. Misoprostol for second trimester pregnancy termination in women with prior caesarean: a systematic review. Br J Obstet Gynecol 2009;116(9):1151-7.

21. Goyal V. Uterine rupture in second-trimester misoprostol-induced abortion after cesarean delivery: a systematic review. Obstet Gynecol 2009;113(5):1117-23.

22. Nayki U, Taner CE, Mizrak T, Nayki C, Derin G. Uterine rupture during second trimester abortion with misoprostol. Fetal Diagn Ther 2005;20:469-71.

23. Atienza MF, Burkman RT, King TM. Midtrimester abortion induced by hyperosmolar urea and prostaglandin F2a in patients with previous cesarean section: clinical course and potential for uterine rupture. Am J Obstet Gynecol 1980;138:55-9.

24. Aslan H, Unlu E, Agar M, Ceylan Y. Uterine rupture associated with misoprostol labor induction in women with previous cesarean delivery. Eur J Obstet Gynecol Reprod Biol 2004;113:45-8. 